\title{
P1 promoter IGF-1 polymorphism and IGF-1, IGF-R, LSF, and TSG 101 expression profile in endometriosis
}

\author{
Wojciech Kwasniewski ${ }^{1}$, Aleksandra Stupak2 ${ }^{\circledR}$, Maria Wolun-Cholewa ${ }^{3}$, \\ Agnieszka Fronczek ${ }^{4}$, Anna Kwasniewska², Jan Kotarski ${ }^{1}{ }^{\mathbb{B}}$, \\ Grzegorz Polak ${ }^{1}$, Anna Gozdzicka-Jozefiak ${ }^{5}$ [] \\ ${ }^{1}$ Department of Gynecological Oncology and Gynecology, Medical University of Lublin, Poland \\ ${ }^{2}$ Department of Obstetrics and Pathology of Pregnancy, Medical University of Lublin, Poland \\ ${ }^{3}$ Department of Cell Biology, Poznan University of Medical Sciences, Poznan, Poland \\ ${ }^{4}$ Department of Patomorphology, Independent Clinical Hospital No. 1, Lublin, Poland \\ ${ }^{5}$ Department of Molecular Virology, Molecular Biology Techniques Laboratory, Adam Mickiewicz University, Poznan, Poland
}

\begin{abstract}
Objectives: The presence of the endometrium outside the uterine cavity affects about $10 \%$ of women of childbearing age. Studies of the progression of endometriosis to cancer have been supported by numerous evidences of gene expression or gene defect caused by oxidative stress and inflammation. We decided to check the expression of selected factors responsible for the proliferation, as in the stages of neoplasia.

Material and methods: A group of 80 women with ovary localization of endometriosis was qualified for research. The control group was 90 patients with ovarian simplex or follicular cysts. The DNA isolation, immunohistochemical analysis of IGF 1, IGF-R, TSG 101, and LSF expressions with a quantitative scoring of slides and electron microscopy was performed. Results: The IGF-1-immunopositive cells in the reference group were in statistically significantly higher number compared to the cells forming the foci of endometriosis $(p=0.0282)$. However, the number of IGF-R-immunopositive cells was comparable to the endometriosis $(p=0.1264)$. In the control group, the number of LSF-immunopositive cells was statistically significantly higher in comparison to endometriosis foci ( $p=0.000001)$, but the number of TSG 101-immunositive cells was comparable to endometriosis foci $(p=0.3834)$. A weak negative correlation between the number of cells expressing the TSG 101 factor and the IGF-1 receptor was found in the endometriosis group $(r=-0.26, p=0.0196)$. The analysis of CA single nucleotide polymorphism in the DNA isolated from both groups showed a comparable incidence of MSS and MSI-L genotypes $\left(\mathrm{chi}^{2} \mathrm{p}=0,9160\right)$.

Conclusions: How these factors affect the development of endometriosis and whether they could be helpful in the diagnosis requires further research.
\end{abstract}

Key words: endometriosis; molecular biology; IGF-I CA (19) P1IGF-I repeats; IGF-; LSF; TSG 100

Ginekologia Polska 2022; 93, 10: 775-786

\section{INTRODUCTION}

The classical definition of endometriosis (E) defines endometriosis as the presence of the ectopic stroma of the endometrium and the glands as being outside the uterine cavity and the uterine muscles [1]. It is a chronic disease affecting about $10 \%$ of women of childbearing age, usually leading to dysmenorrhea, dyspareunia, pelvic pain, infertility and malignant transformation [1-4]. An evalua- tion of the incidences of the malignant transformation of endometriosis is difficult to determine because the strict criterion is to show a histologically proven transition from benign precursors to neoplastic lesions [5]. Nevertheless, a malignant transformation of endometriosis is found in $0.6-0.8 \%$ of women with ovarian endometriosis and in $1 \%$ of women with extragonadal endometriosis [6-8]. However, incidences of malignancies in surgically confirmed endo- 
metriosis are higher than 10\% [9]. Cancers associated with endometriosis, including the most common peritoneum, ovary and fallopian tube cancers, are a diverse group of disorders that include biological behavior from benign to malignant. Anatomically, changes are divided into gonadal (80\%) or extragonadal (20\%) changes [10].

Studies of the progression of endometriosis to cancer have been supported by numerous evidences of gene expression and gene defects [11]. The studies undertaken to identify the gene responsible for endometriosis showed a loss of heterozygosity in PTEN mutations (20\%), beta-catenin mutations (16-54\%), KRAS mutations (4-5\%), microsatellite instability (13-50\%) and ARID1A mutations $(40-50 \%)$ [12-16]. It has been proved that, in ectopic endometrium cells collected in the proliferation phase, there is an increased expression of 191 genes and the silencing of 100 genes in relation to the eutopic endometrium [17].

Mandai et al. [18] showed that microenvironmental factors, including oxidative stress and inflammation, play a key role in the carcinogenesis associated with endometriosis. It has been shown that iron-induced oxidative stress leads to DNA damage, which may be a key factor in the early stage of the malignant transformation process of endometriosis. Hoon Kim et al. [16] showed a relationship between endometriosis and polymorphism IGF-2 $820 \mathrm{G}>\mathrm{C}$ in a group of Korean women and suggested that it is a genetic factor that may be associated with the development of endometriosis in Korean women. Several studies suggest that insulin-like growth factor 1 (IGF-1) has been implicated in the pathogenesis of endometriosis.

IGF-1 is a peptide hormone which plays a pivotal role in regulating cell proliferation, differentiation and apoptosis [19]. The IGF 1 gene is located in the long arm of chromosome $12(12 q 22-24,1)$ and covers about $90 \mathrm{kbp}$. The gene includes 6 exons separated by very long (1.9-50kbp) introns. Two promoters - P1 and P2 - regulate the transcription of the gene. Nearly $90 \%$ of IGF1 transcripts is under the regulation of the $\mathrm{P} 1$. This promoter region of the human genome consists of 322 nucleotides located in the region of 5' UTR and exon 1 in the regulatory region in 1630bp. 5' Cytosine-adenosine (CA)n repeats in the $\mathrm{P} 1$ promoter region of the IGF 1-gene, and $1 \mathrm{~kb}$ upstream of the transcription site are highly polymorphic microsatellites. The number of (CA)n repeats range from 10 to 24 and many studies suggest that this inversely correlates with the transcription activity of the IGF 1 gene. IGF-1 is predominantly produced by hepatocytes and released into the serum of the peripheral circulating blood [20]. This factor may be also synthesized in the cells of various tissues (ovary, endometrium, breast, lung). The serum level of free IGF 1 is affected by six IGF binding proteins.
IGF1 activates intracellular signaling pathways by binding to their cognate receptor IGF1R and, with a lower affinity, to a noncognate receptor (e.g., insulin). Most IGFBs compete with IGF1 to bind with the receptors and to antagonize the IGF function, while some (e.g. IGFBP2) amplify IGF signaling [21]. The interaction between the IGF 1 and IGF 1R results in the trans-autophosphorylation of the intracellular portion of the receptor and the subsequent recruitment of downstream signaling adaptor proteins which induces the activation of phosphoinositide 3'-kinase (PI3K) and mitogen-activated protein kinases (MAPK) pathways, which results in the stimulation of cellular proliferation and cell motility and the inhibition of apoptosis [22]. MAP kinases participate in the phosphorylation by way of a variety of transcription factors which are implicated in the controlling and expression of the genes essential for cell proliferation.

The LSF transcription factor is a target of the MAP kinases, specifically pp44/42 (ERK1/2) [23]. This factor plays a key role in activating the gene-encoding thymidylate synthetase (Tyms) at the G1/S transition and cell cycle progression. LSF, also known as LBP-1c and TFCP2, was detected as a transcriptional activator factor of the late Simian virus 40 (SV40) promoter in HeLa cells [24]. Subsequently, it was discovered that LSF is expressed in all mammalian cell types by playing an important role in cells cycle regulation. LSF is a transcription factor regulating controlling the gene expression of angiogenesis, tumor proliferation and invasion. Additionally, it activates two cell survival-regulating pathways - MEK/ERK and NF-kB. The Ras/Raf/MEK/ERL signaling pathway regulates various cellular functions including cell cycle progression, migration, proliferation, survival and angiogenesis [25]. Advances have been made in targeting the Ras/Raf/MER/Erk mitogen-activated protein kinase cascade with MEK inhibitors for cancer treatment [26]. Recently, LSF was identified as an oncogene in hepatocellular carcinoma (HCC) [27]. The LSF protein levels are generally low and constant in many cells; however, it is highly upregulated in tumor cells, particularly in HCC as well as in colorectal cancer [28]. LSF is a transcription factor which also participates in the expression of the tumor susceptibility gene 101(TSG 101). The TSG 101 protein is implicated in multiple cellular functions such as cytokinesis, protein ubiquitination, transcriptional regulation, cell cycle and proliferation and endosomal sorting and trafficking. The overexpression of TSG101 has been reported in many cancers, such as colorectal carcinoma, gallbladder carcinoma or ovarian cancer [29, 30]. It was suggested that an elevated TSG101 level is associated with a poor prognosis for ovarian cancer [29]. TSG 101 is also included in the MDM2-53 regulatory circuit. MDM2 is a transcriptional target of p53 and binding MDM2 to the $\mathrm{N}$-terminus of the $\mathrm{p} 53$ protein promotes its degradation 
by the ubiquitin-protein. Thus, a loss of TSG101 would result in the upregulation of p53 [31].

\section{Aim of the study}

Previous studies have unambiguously indicated that in endometriosis there is an impairment in the activity of many genes, especially those involved in the process of angiogenesis, adhesion, proliferation, immune response, proteolysis, differentiation and apoptosis.

For these reasons, by treating endometriosis as a proliferative disease and based on the analysis of the literature describing the stages of neoplasia, we decided to check the expression of the selected factors responsible for proliferation, namely:

1. the IGF-1 factor and its receptor,

2. an assessment of the microsatellite instability of the IGF-1 P1 promoter in tissues,

3. the TSG factor - a tumor suppressor whose function is related to excluding the expression of specific genes, mainly by controlling normal cell growth and preventing the cells from obtaining a cancerous phenotype,

4. the LSF factor - an apoptosis inhibiting factor, the increased expression of which may be responsible for the survival of endometrial cells at ectopic sites, and

5. an assessment via electron microscopy of stromal and eutopic and ectopic endometrium cells.

\section{MATERIAL AND METHODS Patients}

The clinical material used to assess the expression of IGF 1, IGF-R, TSG 100 and LSF, and an analysis of the CA promoter $\mathrm{P} 1$ region repetitions of the IGF1 gene, included tissue fragments embedded in paraffin blocks (Sigma-Aldrich, St. Louis, MO, USA) in patients who underwent surgery at the Department of Gynecologic Oncology and Gynecology in Lublin (Poland) from November 2010 until December 2017.

The study group consisted of 100 women with ovary localization of endometriosis. Of the 100 women, 80 women qualified for further research. The biological material collected from 20 patients was rejected for technical reasons (insufficient DNA, unreliable results, etc.). According to the revised classification by the American Fertility Society [25], women were classified as endometriosis degree I, 34 as degree II, 10 as degree III and 11 as degree IV [32]. Diagnosis and reclassification after surgery treatment was carried out histologically by two independent pathologists.

The reference group was 100 patients hospitalized in the Department with a suspicion of ovarian cancer, and in which the histopathological results found ovarian simplex or follicular cysts. 90 patients qualified for the final control group for the same reasons given above.
The average age of the patients with endometriosis was $33.8 \pm 8.1$ [range: $20-43$ ] years. The average age in the reference group was $32 \cdot 6 \pm 7,3$ [range: $20-46](p=0,88)$.

\section{Stages of research \\ DNA isolation from paraffin-embedded tissue fragments}

Paraffin-embedded tissue blocks were fixed in 10\% buffered formalin (Sigma-Aldrich) and cut into two or three 4- $\mu \mathrm{m}$ sections using a microtome (model SM 2000R; Leica Biosystems $\mathrm{GmbH}$, Nussloch, Germany) with a razor blade (Feather Microtome Blade Type R35; Feather Safety Razor Co., Ltd., Osaka, Japan). The blade was cleaned with ethanol between the samples. A fresh cutting blade was used for each of the paraffin blocks. The obtained sections were placed in a $1.5 \mathrm{~mL}$ test tube containing polypropylene (Sigma-Aldrich) and stored at $4^{\circ} \mathrm{C}$ for future analysis.

The isolation of the DNA from the archived paraffin tissues was performed by a Maxwell ${ }^{\circledR} 16$ Instrument for Nucleic Acid and Protein Purification device (cat. no. AS1250; Promega Corp., Madison, WI, USA). It was equipped with designated software for automated DNA isolation with use of the Maxwell 16 FFPE Plus LEV DNA Purification kit (cat. no. AS1135; Promega Corp.). The quantitative analysis of the obtained DNA was performed using a Novaspec II automatic spectrophotometer (GE Healthcare, Little Chalfont, UK).

The DNA was used for the polymerase chain reaction (PCR) amplification followed by an analysis of (CA)n repeats in the P1 promoter region of the IGF-1 gene.

\section{Analysis of the CA repeats in the $P 1$ region of IGF-1}

An investigation of the (CA)n repeats of the IGF-1 gene located $1 \mathrm{~kb}$ upstream of the transcription start site was done by using PCR and fragment analysis. The PCR was performed in $15-\mu$ l volumes containing of $100 \mathrm{ng}$ genomic DNA, 3.75 pmol forward primer (5'-AAG AAA ACA CAC TCT GGC AC-3') fluorescently labeled with FAM (Polish Academy of Science, Warsaw, Poland), 3.75 pmol reverse primer (5'-ACC ACT CTG GGA GAA GGG TA-3'; Roche Diagnostics, Mannheim, Germany), $0.01 \mathrm{mM}$ deoxynucleotide triphosphate (Polish Academy of Science), $1.5 \mathrm{mM} \mathrm{MgCl} 2$ (Fermentas, Poznan Poland), 1X PCR buffer (Fermentas) and 0.6U HiFi DNA polymerase (cat. no. N1003 05; Novazym, Poznan, Poland). The analysis was performed using a thermal cycler (Tgradient Thermocycler, Biometra, Goettingen, Germany). The amplification cycles included one cycle of $4 \mathrm{~min}$ at $94^{\circ} \mathrm{C}$ : $28 \mathrm{PCR}$ cycles consisting of $5 \mathrm{sec}$ at $94^{\circ} \mathrm{C}$ (denaturation), $30 \mathrm{sec}$ at $60^{\circ} \mathrm{C}$ (annealing) and $1 \mathrm{~min}$ at $72^{\circ} \mathrm{C}$ (elongation), and a final $30-\mathrm{min}$ elongation step at $65^{\circ} \mathrm{C}$. The PCR product size analysis was completed on an automated $\mathrm{ABI}$ 
3130 sequencer camera XL (Applied Biosystems, Thermo Fisher Scientific, Inc., Waltham, MA, USA) and fixed by comparison with the GS600LIZ internal size markers (Applied Biosystems). The estimation of (CA)n repeat numbers in each of the investigated specimens was based on an extrapolation of the previously developed specific allelic ladder [16]. The ladder marker consisted of 14 sequenced amplifications representing alleles with $7,9,11,13$ and 23 CA repeats.

Tissues were grouped as microsatellite instability-high (MSI-H) when at least 2 of the 5 loci showed MSI [non 19/non19] and as MSI-low (MSI-L) when only one locus showed MSI [19/non 19 and/or non19/19]. If none of the microsatellite sequences was mutated, the tumor was classified as microsatellite stable [MSS; 19-19] [13-14].

\section{Immunohistochemical analysis}

During the immunohistochemical analysis, the sections were placed on the surface of warm water where, under the influence of the elevated temperature and initially wrinkled, they were gently deposited onto salinized basic slides covered with amorphous silicon dioxide to increase the stickiness of the section (Menzel-Gläser, Germany, cat. No. J1800AMNZ). Permanent gluing of the sections was obtained by placing the slides in an oven at $60^{\circ} \mathrm{C}$ for a period of about 12 hours. After this time, the preparations were cooled to room temperature $\left(20-25^{\circ} \mathrm{C}\right)$ and stored refrigerated at $2-8^{\circ} \mathrm{C}$ until IHC staining.

For the immunohistochemistry (IHC) tests, those that showed the most tissue and the lowest number of necrotic lesions were selected. Histopathological reclassification was performed, according to FIGO criteria, by two independent pathomorphologists (J.S. M.W.) who formed the test group for the evaluation of the immunohistochemical evaluation of the expression of the examined genes.

\section{Immunohistochemical analysis of IGF-1 and IGF-R expression}

Immunohistochemical staining for IGF-1 and IGF-R was completed using Human IGF-1 Antibody; Antigen Affinity-purified Polyclonal Goat lgG; (cat. no: AF-291-NA); stock: $200 \mu \mathrm{g} ; \mathrm{R} \& D$ Systems ${ }^{\circ}$ and Human/Mouse IGF-1 R Antibody; Antigen Affinity-purified Polyclonal Goat IgG, (cat.

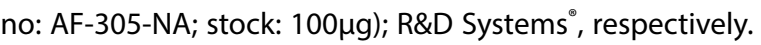
For the dilution of antibodies, a sterile PBS buffer was used (buffered, without calcium and magnesium ions, $\mathrm{pH}$ 7.4) (cat. well.: H15-002, PAA Laboratories GmbH, Austria).

In the ImmPRESSTM staining system a secondary antibody was used which was conjugated with a micropolymeric circuit consisting of tightly packed, very active molecules of peroxidase. Due to the application of the micropolymeric reagent it was possible to achieve a high sensitivity and sharp tone, showing the localization of the antigen in the tissue against a minimal background. The heat unmasking procedure of the antigenic determinant was carried out in a MLL 547 water bath (AJL Electronic, Krakow, Poland) in buffer Antigen Unmasking Solution (Tris based, high $\mathrm{pH}$ ), heated to a temperature of $95-99^{\circ} \mathrm{C}$ (cat. well. $\mathrm{H}-3301-250$, Vector Laboratories, CA, USA).

The activity of the endogenous peroxidase was blocked after the incubation of tissue sections in a $3 \%$ solution of hydrogen peroxide (H2O2) (Pharmaceutical Production Company Hasco-Lek S. A. Wroclaw, Poland), twice for 5 minutes. The sections were then incubated in a blocking serum, the manufacturer of the kit (ready-to-use $2.5 \%$ normal horse serum). After 20 minutes polyclonal primary antibodies were applied, directed at the human antigen for 30 minutes. In accordance with the manufacturer's recommendations a dilution was used, in which the final concentration of both antibodies (IGF-1 and IGF-1 R) was $2.5 \mu \mathrm{g} / \mathrm{mL}$. The reaction was visualized via DAB Peroxidase Substrate incubation for 5 minutes (Cat.Well. SK-4100, Vector Laboratories, California, USA). After washing the sections in distilled water (twice for five minutes) a contrasting incubation was performed in which the nuclei of the cells were stained via hematoxylin (cat. No. 468860448 ABSORBS S. A., Gliwice, Poland). Finally, the slides were dehydrated according to the previously described procedure and placed in a medium (Shandon Consul-MountTM Histology Formulation, cat. No. 9990440, Thermo Scientific, Massachusetts, USA).

\section{Immunohistochemical analysis of TSG 101 and LSF expressions}

The entire process, starting with the preparation of the histopathological preparation, via the deparphinisation and antigen detection stage to the tissue staining stage using immunohistochemical methods, was carried out automatically in the apparatus managed by a computer with NexES software containing optimized staining protocols. The following antibodies were used: i / Anti-LSF Purified Monoclonal Mouse lgG1 (Clone: 14 / LSF) (1:50 dilution); BDTransduction LaboratoriesTM, Cat. No 610818, BD Biosciences (New Jersey, USA), ii / TSG 101 (C-2): sc-7964 Mouse Monoclonal Antibody (1:50 dilution) Santa Cruz Biotechnology, Inc. (Texas, USA); and Antibody Diluent, Cat. No. 251-018 (Roche, Arizona, USA) was used to dilute the antibodies.

The final process of dewatering and rinsing in xylene and closing within the medium was carried out manually. According to the manufacturer's instructions, the following reagents were used: Ventana Medical Systems, Inc., Roche (Arizona, USA): Reaction Buffer Concentrate (10x), Cat. Well. 950-300; EZ Prep Concentrate (10x) solution, Cat. Well. $950-$ 102; Cell Conditioning 1 (CC1), Cat. Well. 950-124, Liquid Coverslip (High temp., Predilute, LCS), Cat. Well. 650-010; Ultra View Universal DAB Detection Kit, Cat. Well. 760-500; 
Reaction Buffer (10x), Cat. Well. 950-300; Bluing Reagent, Cat. Well. 760-2037; Hematoxylin II, Cat. Well. 790-2208; Prep Kit, Cat. Well. 1637700. Dispereshers were used to deliver the antibodies to a VENTANA stainer.

\section{Quantitative scoring of slides}

The estimation of the number of IGF-1-, IGF-R-, TSG 101- and LSF-immunopositive cells was performed by 2 independent pathologists using the Cell-2 software, version 4.1 (Poznan University of Medical Sciences, Poznan, Poland). The evaluation method was established on the analysis of the color distribution and their optical density. The software recognizes cells based on a higher optical density in relation to the optical density of the background and indicates them as immunonegative or immunopositive in accordance with their optical density. To determine the fraction of positive cells depending on the variables, the number of immunopositive cells was split by the total number of cells. At least 5000 cells were counted each time for each of the analyzed groups.

\section{Electron microscopy}

For the electron microscopy analysis, the tissue specimens obtained from the reference and investigated groups were immersed at $20{ }^{\circ} \mathrm{C}$ for at least two hours in a fixative solution containing $8 \%$ glutaraldehyde (Taab, Berkshire, UK) and $8 \%$ paraformaldehyde (Merck, Darmstadt, Germany) buffered with $0.1 \mathrm{M}$ phosphate buffer (Merck), pH 7.3. After immersion, the specimens were cut and incubated overnight in a fixative solution. Then they were rinsed for $60 \mathrm{~min}$ in $0.1 \mathrm{M}$ phosphate buffer, $\mathrm{pH} 7.3$, and post fixed in $2 \%$ OsO4 in $0.1 \mathrm{M}$ phosphate buffer for 120 minutes (Merck). The specimens were dehydrated in $\mathrm{C}_{2} \mathrm{H}_{5} \mathrm{OH}$, block-stained with alcoholic uranyl acetate and embedded in Spurr's medium (Merck). After contrasting, the ultrastructure of epithelial cells and fibroblasts were assessed using JEOL 100 Transmission Electron Microscope.

\section{Statistical analysis}

Any correlations or differences between the analyzed parameters were verified using multiway tables. Their homogeneity or independence were verified using the $x 2$ test. The analysis of differences between the studied sub-groups was performed by non-parametric tests due to the skewed distribution of measurable parameters evaluated on the basis of the Shapiro-Wilk test. A comparison of the two independent groups was performed using the Mann-Whitney $\mathrm{U}$ test. To compare more than 2 groups, the Kruskal-Wallis test and multiple comparisons/post-hoc tests were performed. Bivariate correlations between the study variables were determined by calculating Spearman's rank correlation coefficients. The analysis assumed a 5\% error of inference and the associated significance level of $p<0.05$ was considered to indicate a statistically significant difference. The statistical analyses were made using Statistica software version 8.0 (StatSoft, Krakow, Poland).

\section{Ethics statements}

Written informed consent was obtained from all participating subjects. The study was accepted by the Ethics Committee of the Medical University of Lublin (Lublin, Poland; Resolution of the Bioethics Committee no. 0254/151/2015 and 0254/90/2017) and performed in accordance with the principles of the Helsinki Declaration.

\section{RESULTS}

\section{IGF 1 and IGF-1R expression analysis}

In the primary stage of the study, immunohistochemistry was used to confirm the presence of IGF-1 and IGF-1R protein in the tissue fragments. The study examined a total of 80 specimens from the endometriosis group and 90 specimens from the reference group. The results are graphically presented in Figure 1. An example of the expression of IGF-1 protein and its receptor is shown in Figure 2.
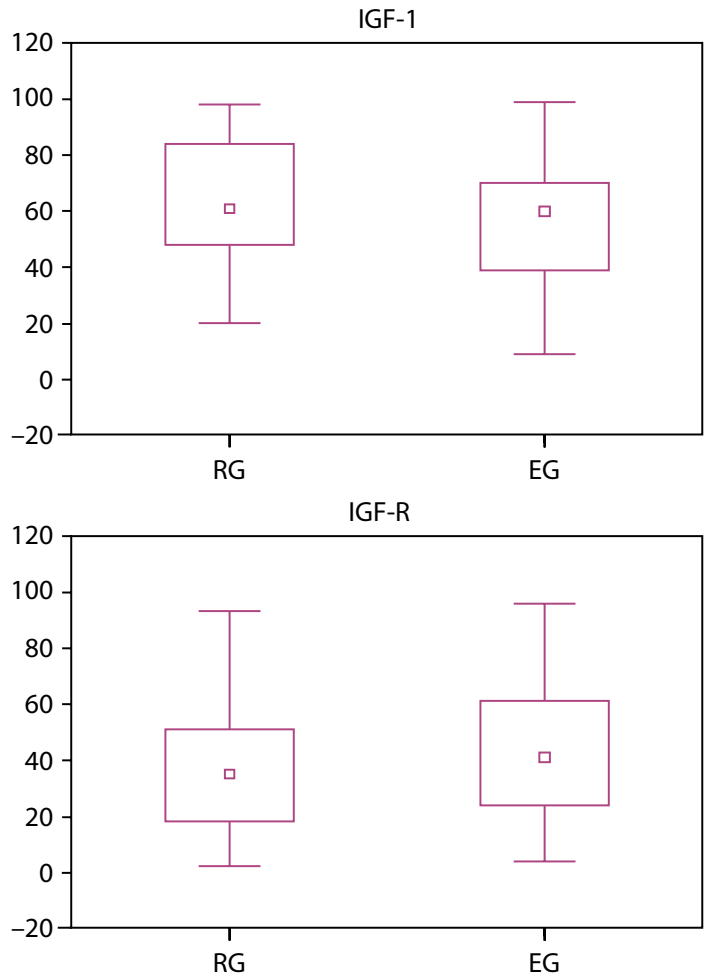

Figure 1. IGF-1 and its receptor (IGF-R) expression in the endometrial tissues in the reference and endometriosis groups. The left axis indicates the percentage of immunopositive cells. The small squares are the median value. The big boxes are the $25-75 \%$ range and the bars the minimum-maximum range; IGF — insulin-like growth factor; IGF-R - receptor for insulin-like growth factor; RG — reference group; EG - endometriosis 

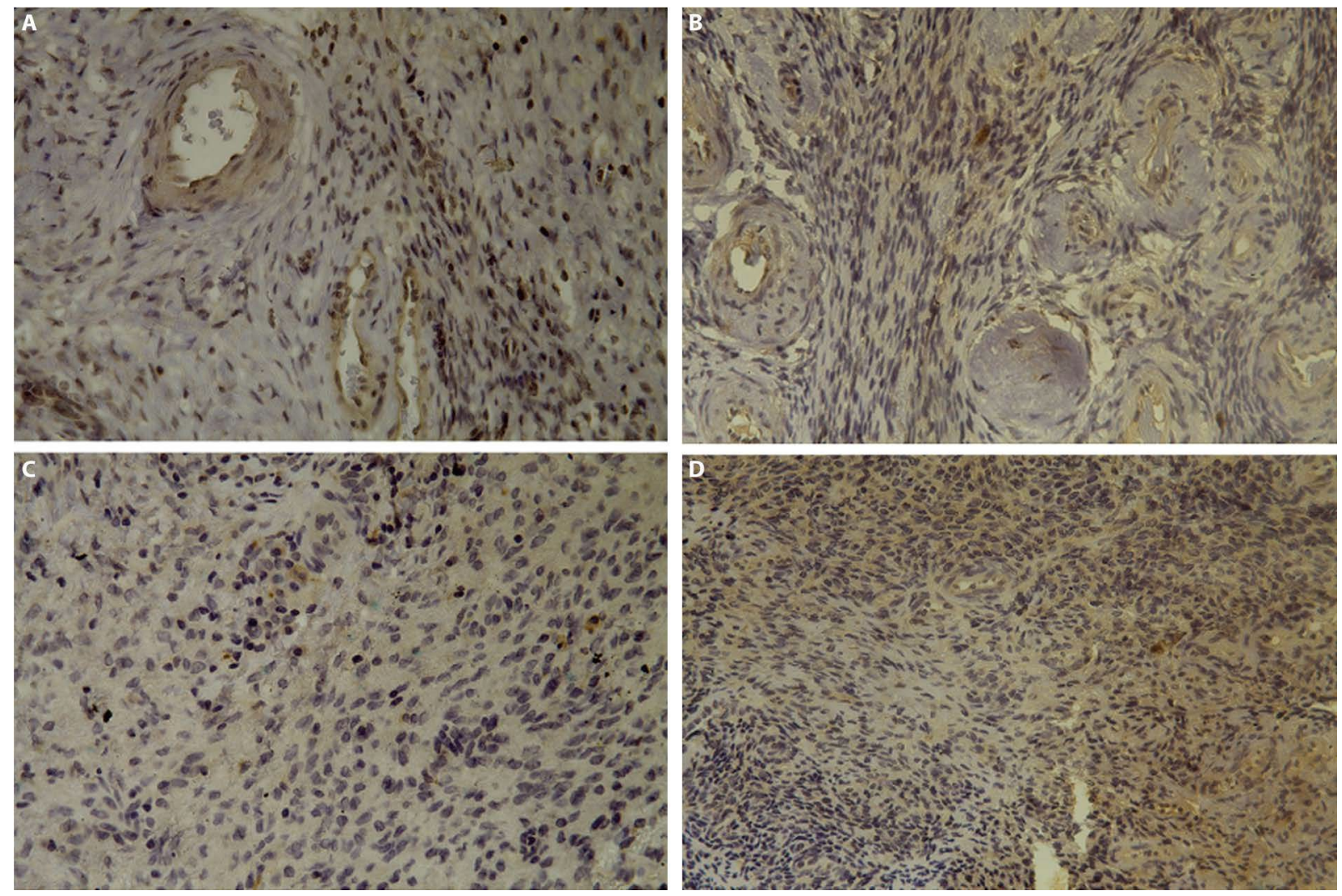

Figure 2. Immunohistochemical analysis of IGF-1 and its receptor (IGF-R) expression in the endometrial tissues in the reference and the endometriosis groups. (A) Reference group, IGF-1 expression; (B) Reference group, IGF-R expression; (C) Endometriosis, IGF-1 expression; (D) Endometriosis, IGF-1 expression (magnification, $\times 100$ )

Based on Figure 1 it will be observed that, in the tissues from the reference group, the number of the IGF-1-immunopositive cells was statistically significantly higher compared to the cells forming the foci of endometriosis (U Mann-Whitney U test, $\mathrm{p}=0.0282$ ). However, the number of IGF-R-immunopositive cells was comparable to the cells forming the foci of endometriosis (test of Mann-Whitney $U ; p=0.1264$ ).

We then analyzed the effect of microsatellite (CA) allele length in the IGF1 gene P1 promoter on the IGF1 expression.

Allelic distribution of (CA)n repeats in the IGF1 gene P1 promoter in DNA isolated from serum and tissue samples from all women with endometriosis and the reference group.

DNA was isolated from the tissue of the reference group and the endometriosis patients and any correlation among the occurrences of $C A$ repeats situated in the $\mathrm{P} 1$ promoter region of the IGF1 gene was investigated. The IGF1 genotype distribution is presented in Table 1. The length range of CA repeats in the DNA study was 11 to 21 .

Depending on the single nucleotide (CA) polymorphism in the reference group we recognized two genotypes: MSS, which carried (CA) 19 repeat alleles and MSI-L which carried only one CA 19 allele. In the endometriosis group we separated three genotypes: MSS, which carried (CA)19 repeat alleles; MSI-L, which carried only one CA 19 allele, and MSI-H which lacked $(C A) 19$ repeat alleles.

The analysis of the CA repetition in the case of the DNA isolated from the tissues collected during the treatments from the reference and the endometriosis groups showed a comparable incidence of MSS and MSI-L genotypes (chi square $p=0,9160, d f=1$, Tab. 1 ).

A subsequent statistical analysis of the results showed that, in the reference group, the type of IGF-1 polymorphism had no effect on the frequency of IGF 1-immunopositive cells (Mann-Whitney U-test, $p=0.5152$, Fig. 3 ). In those cells forming endometriosis, on the other hand, this information is important and indicates that the number of IGF-1-immunopositive cells is statistically significantly lower in the stable profile of MSS compared to the instability of MSI-L and MSI-H (Kruskal-Wallis test, $\mathrm{p}=.0006$; Dunn's post-test: MSS vs. MSI-L $p=0.000513$, MSS vs. MSI-H $p=0.002691$, MSI-L vs. MSI-H $\mathrm{p}=1.00$, Fig. 3).

\section{Expression analysis of LSF and TSG 101 factors}

LSF is also an important factor which, like IGF-1, may be applied to differentiate cyst cells from endometriosis. It was found that in the cells of tissues forming the reference 


\begin{tabular}{l}
$\begin{array}{l}\text { Table 1. Comparison of microsatellite instability evaluation (CA } \\
\text { repeat) in DNA isolated from paraffin block tissues of patients from } \\
\text { the study and the reference groups }\end{array}$ \\
\hline
\end{tabular}

${ }^{a}$ Comparison of CA repeats in DNA isolated from tissue between reference and endometriosis group; IGF — insulin-like growth factor; MSS — microsatellite stable; MSI-L — microsatellite instability low; MSI-H — microsatellite instability high; $\mathrm{N}$ - number of subjects with the respective genotype

group, the number of LSF-immunopositive cells is statistically significantly higher in comparison to the cells forming endometriosis foci (Mann-Whitney U test, $p=0.000001$, Fig. 4). In subsequent studies it was decided to check whether the changes in the expression of LSF influence the expression of theTSG 101 protein. It was found that in the cells of tissues from the reference group, the number of TSG 101-immunositive cells is comparable to the cells forming the endometriosis foci (Mann-Whitney U test, $p=0.3834$, Fig. 4).

An example of the expressions of LSF and the TSG 101 protein, detected by immunohistochemistry, is shown in Figure 5.

\section{Correlation analysis of IGF-1, IGF-R, LSF and TSG 101 expression}

A statistical analysis based on Spearman Rank Order Correlations showed no correlation between the number of
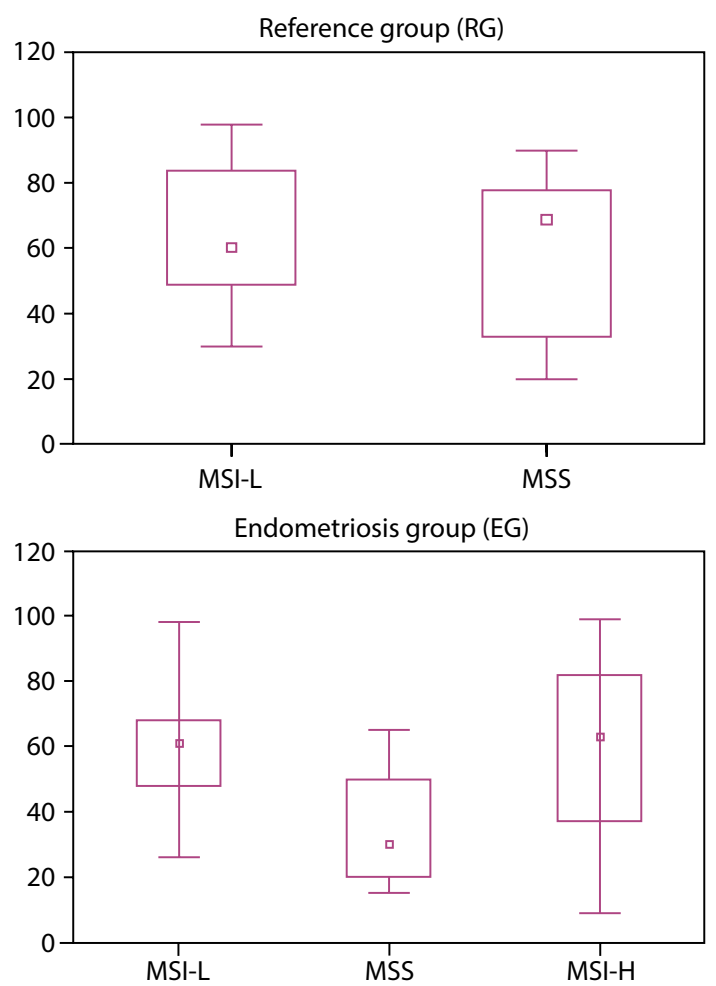

Figure 3. IGF-1 expression in the endometrial tissues in the reference and endometriosis group according to the microsatellite promoter P1 status of the IGF-1 gene. The left axis indicates the percentage of immunopositive cells. The small squares are the median value, and the boxes are the $25-75 \%$ range with the bars of the minimummaximum range; $\mathrm{RG}$ - reference group; $\mathrm{EG}$ - endometriosis; MSI H - microsatellite instability high, MSI-L — microsatellite instability-low, MSS — microsatellite stable

cells expressing IGF-1, IGF-R, LSF and TSG 101 in the reference group ( $p>0.05$ ). On the other hand, a weak negative correlation between the number of cells expressing the TSG 101 factor and the IGF-1 receptor was found in the endometriosis group (Spearman Rank Order Correlations $r=-0.26, p=0.0196$ ).

\section{Electron microscopy}

In the reference group, most epithelial cells have an elevated nucleocytoplasmic ratio and nuclei with a high amount of heterochromatin and a specific chromatin margination - dark and with high electron density mitochondria (Fig. 6A). In the stroma, cells with low electron-density nuclei and numerous collagen fibers (indicated by arrows) were observed (Fig. 6B).

In the endometriosis, heterochromatic cell nuclei were present both in the glands and the stroma, with and in an irregular shape (Fig. 6C and 6D). In the cytoplasm, low electron density mitochondria and collagen fibers (indicated by arrows) were observed. 

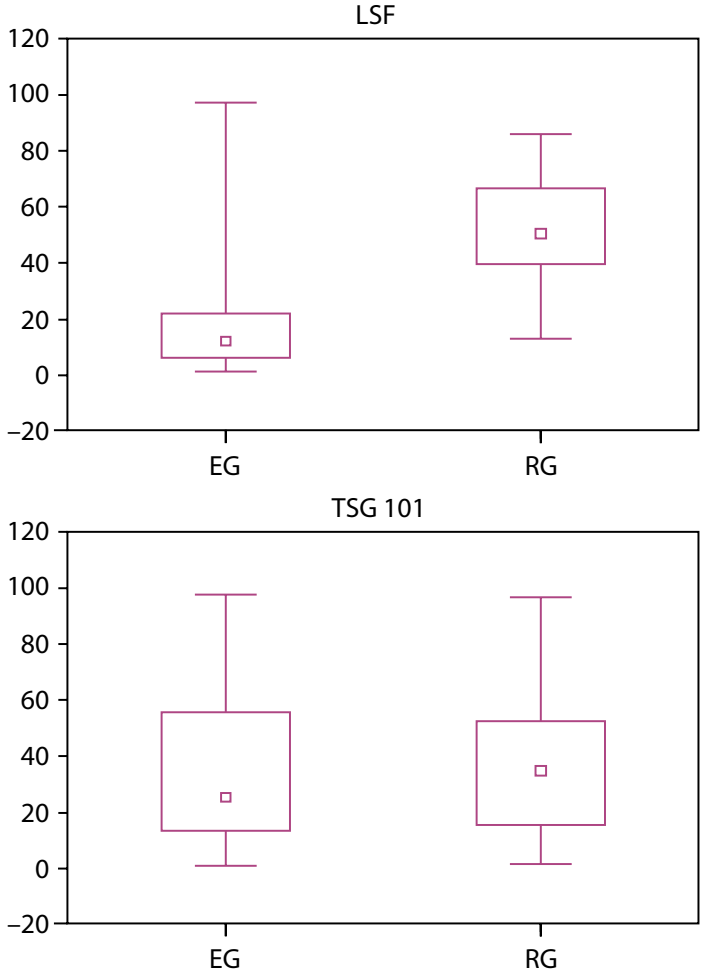

Figure 4. LSF and TSG 101 expression in the endometrial tissues in the reference and endometriosis group. The left axis indicates the percentage of immunopositive cells, the small squares the median value, the boxes the $25-75 \%$ range and the bars the minimum-maximum range; RG - reference group; EG — endometriosis

\section{DISCUSSION}

Endometriosis is defined as the extrauterine growth of the endometrial glands and stroma. About $1 \%$ of women with endometriosis have lesions that undergo neoplastic transformation [5-8].

According to Bischff and Simpson, the neoplastic transformation of endometriosis relates to the accumulation of mutations in the tumor suppressor genes or oncogenes [33]. The etiology of endometriosis remains unclear. Many studies have demonstrated the familiar nature of endometriosis and suggest that the inheritance occurs in a polygenic multifactorial mode. A number of candidate genes have been evaluated for their association with endometriosis, such as genes involved in inflammation, steroid synthesis, detoxification, hormone receptors, estrogen metabolism, adhesion molecules, apoptosis, cell-cycle regulation, growth factors, oncogenes and tumor suppressor genes. These studies have demonstrated the mutations of genes, SNPs, alteration in the loss of heterozygosity, polymorphism in microsatellites or alterations in gene expression [34, 35]. Fung and Montgomery suggest that the most common genetic factors that contribute to the risk of endometriosis are located in regulatory DNA sequences and are responsible for the regulation of gene transcription [36]. Other factors are lifestyle, diet or environmental factors, such as dioxin. Several studies suggest that the insulin-like growth factor 1 (IGF-1) system has been implicated in the pathogenesis of endometriosis [37].

GF are mediators of the interaction between cancer cells and the extracellular matrix or non-neoplastic cells such as myofibroblasts, macrophages and endothelial cells [38]. IGF (insulin-like growth factor), a peptide hormone, plays an important role in mediating and modulating the sex hormone-induced growth and differentiation of endometrial cells $[39,40]$. Studies have shown that IGF-1 is a factor preventing apoptosis and, as a mitogen, it acts on endometrial stromal cells in vitro [41, 42]. It is believed to be one of the mediators for estrogen receptors and other growth factors of signaling pathways $[41,43]$.

The presence of selected elements of the IGF family has been demonstrated in human peritoneal fluid and the increased expression and localization of IGF-1 and its binding proteins has been demonstrated both in the eutopic endometrium, as well as in endometriotic changes [41, 44, 45].

The results of our research indicate that the expression of IGF 1 is higher in reference cells compared to endometriosis cells. Furthermore, this is not related to the $C A$ polymorphism in the regulatory region of the IGF $1 \mathrm{P} 1$ promoter, although many studies imply that the number of $C A$ repeats in the promoter region is inversely associated with the transcriptional activity. In the literature, the contribution of the CA promoter polymorphism is still controversial in clinical disorders such as cancer, diabetes, cardiovascular disease, birth weight and body height, and IGF-1 serum levels $[5,6,46]$.

IGF-1R overexpression with increased AKT activity was detected in the hyperplastic endometrium [47]. However, it is not known whether the expression of IGF-1R and/or IGF-1 is altered in the endometrial eutopic endometrium of women with endometriosis and, if so, what the mechanism underlying the disease may be.

Our previous studies have shown that one of the factors that can be involved in the process of cancer is TSG101 (gene 101 susceptibility to cancer) $[2,48]$. The TSG 101 is a protein with a multiple role in eukaryotic cell. The numerous roles of TGS 101 are facilitated through its domains - UEV (ubiquitin e2 variant), a domain at the $\mathrm{N}$-terminus and a putative DNA-binding motif at its $\mathrm{C}$-terminus. This protein is involved in cytokinesis, protein ubiquitination, transcriptional regulation, cell cycle and proliferation and viral budding.

The silencing of TSG 101 by short interfering RNA in ovarian cancer cells led to the inhibition of cell growth and death. Although TSG101 was initially considered a potential tumor suppressor, the precise role of TSG101 in tumor formation and development is unknown [49]. It has been proposed 

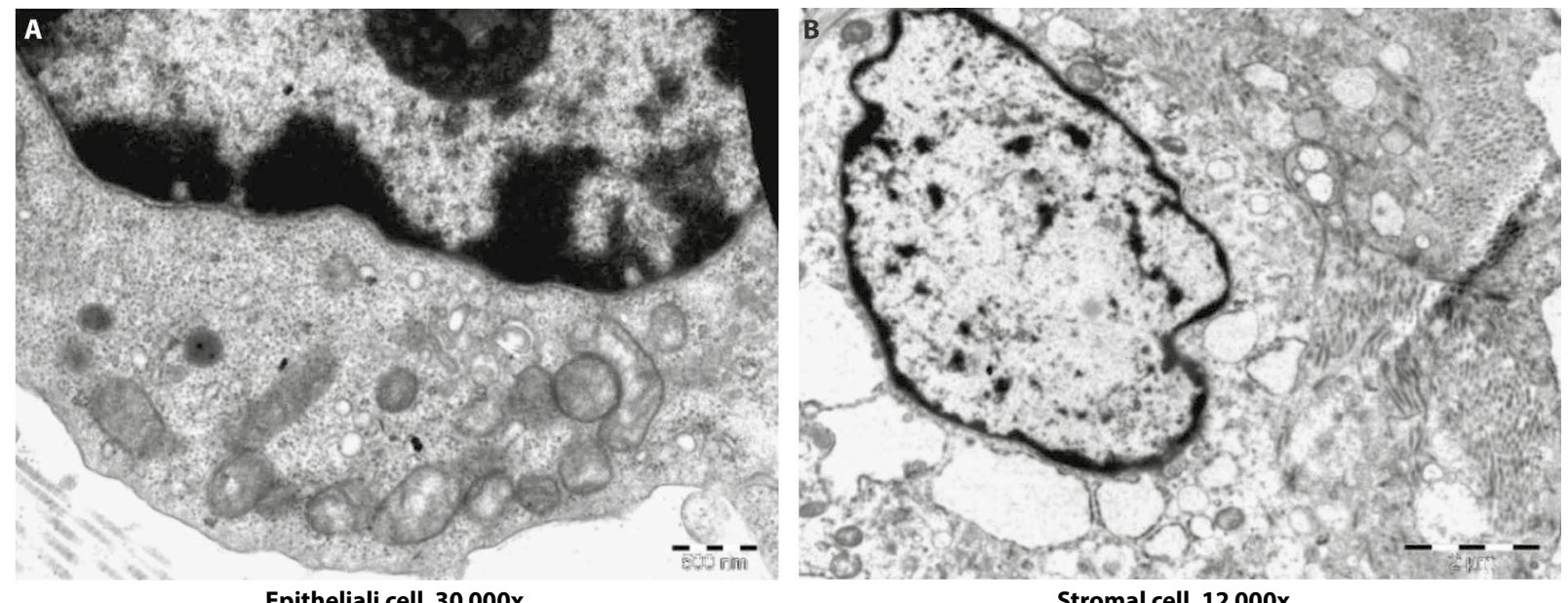

Epitheliali cell, $30000 x$

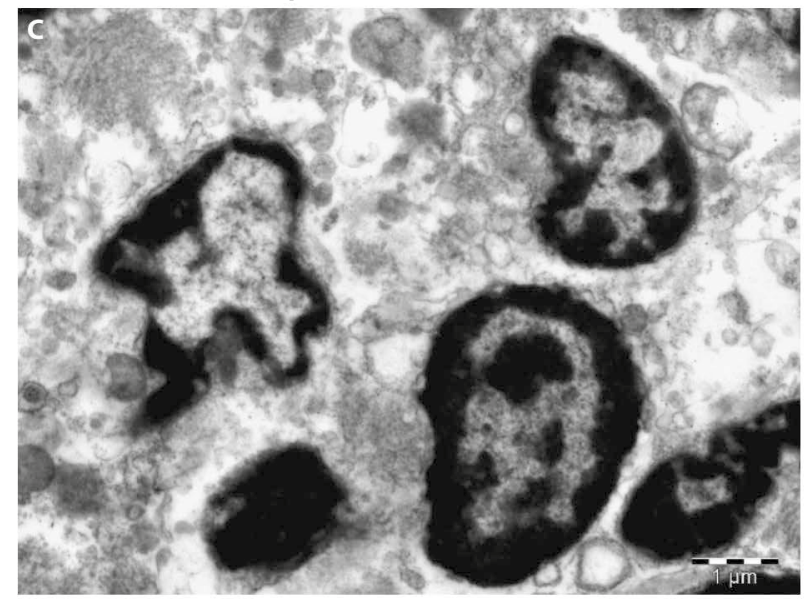

Epitheliali cells, $10000 x$

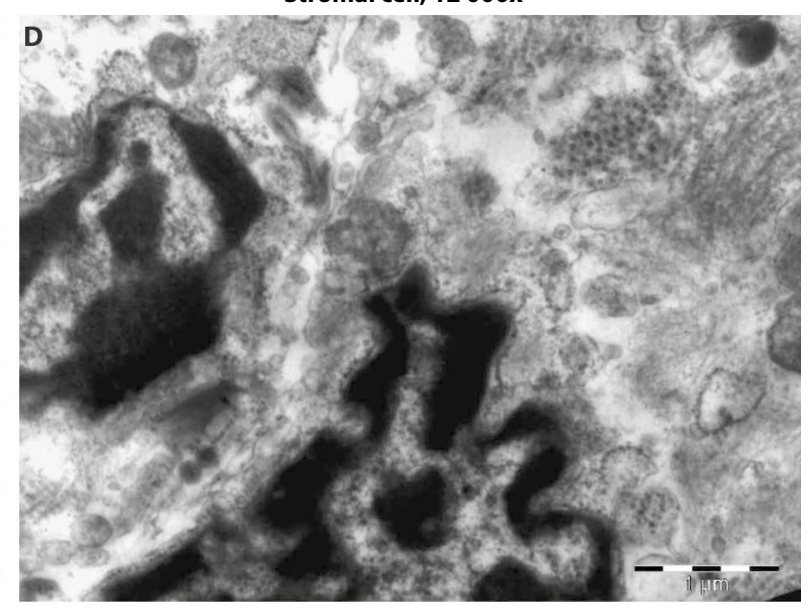

Stromal cells, 15 000x

Figure 5. Immunohistochemical analysis of LSF and TSG 101 expression in the endometrial tissues in the reference and endometriosis groups; (A) Reference group, LSF expression; (B) Reference group, TSG 101 expression; (C) Endometriosis, LSF expression; (D) Endometriosis, TSG 101 expression (magnification, $\times 100$ )

that TSG101 is an important factor in maintaining cellular homeostasis and that the disruption of the TSG101 function leads to transformation [6]. TSG101 is constitutionally expressed in many human tissues. An increased expression of TSG101 was found in the papillary carcinoma of the breast, thyroid, ovarian and gastrointestinal tumors, while downregulation of TSG101 was observed in endometrial and cervical carcinomas $[2,6,49-51]$. The results of our study showed no change in the TSG 101 expression in endometriosis cells compared to that of the controls. One of the factors responsible for regulating the expression of the TSG 101 gene is LSF.

\section{CONCLUSIONS}

Human LSF is a 502 amino acid long peptide with a molecular weight of about $57 \mathrm{kDa}$ [52]. It consists of 2 functional domains. The $\mathrm{N}$-terminal domain is a region of DNA interaction between 67-260 amino acids, structurally similar to the A domain binding p53 / p63/p73 DNA. The C-terminal region is responsible for oligomerization and contains tetramerization and dimerization domains. LSF acts as a transcriptional activator and repressor of various viral and cell promoters $[53,54]$. As a transcription factor, LSF binds DNA primarily as a homotetramer [27]. Fan et al. [55] classified LSF as a further mediator of Notch1 signaling and presented that LSF mediates, at least partially, in Notch-1 induced carcinogenesis. Notch genes code for heterodimer transmembrane receptors which play a key role in maintaining a balance between cell differentiation, proliferation and apoptosis and this may contribute to cervical cancer, colon cancer, head and neck cancer, lung cancer, acute myeloid leukemia and large cell lymphoma [55-61]. The level of LSF protein is generally low and stable in normal cells. However, LSF overexpression is found in human hepatocellular carcinoma (HCC) cells compared to normal hepatocytes and liver, and the level of expression has a significant correlation with the stages and degrees of disease [27, 62]. LSF can function as an oncogene for HCC. Thus, LSF inhibitors rapidly induce 

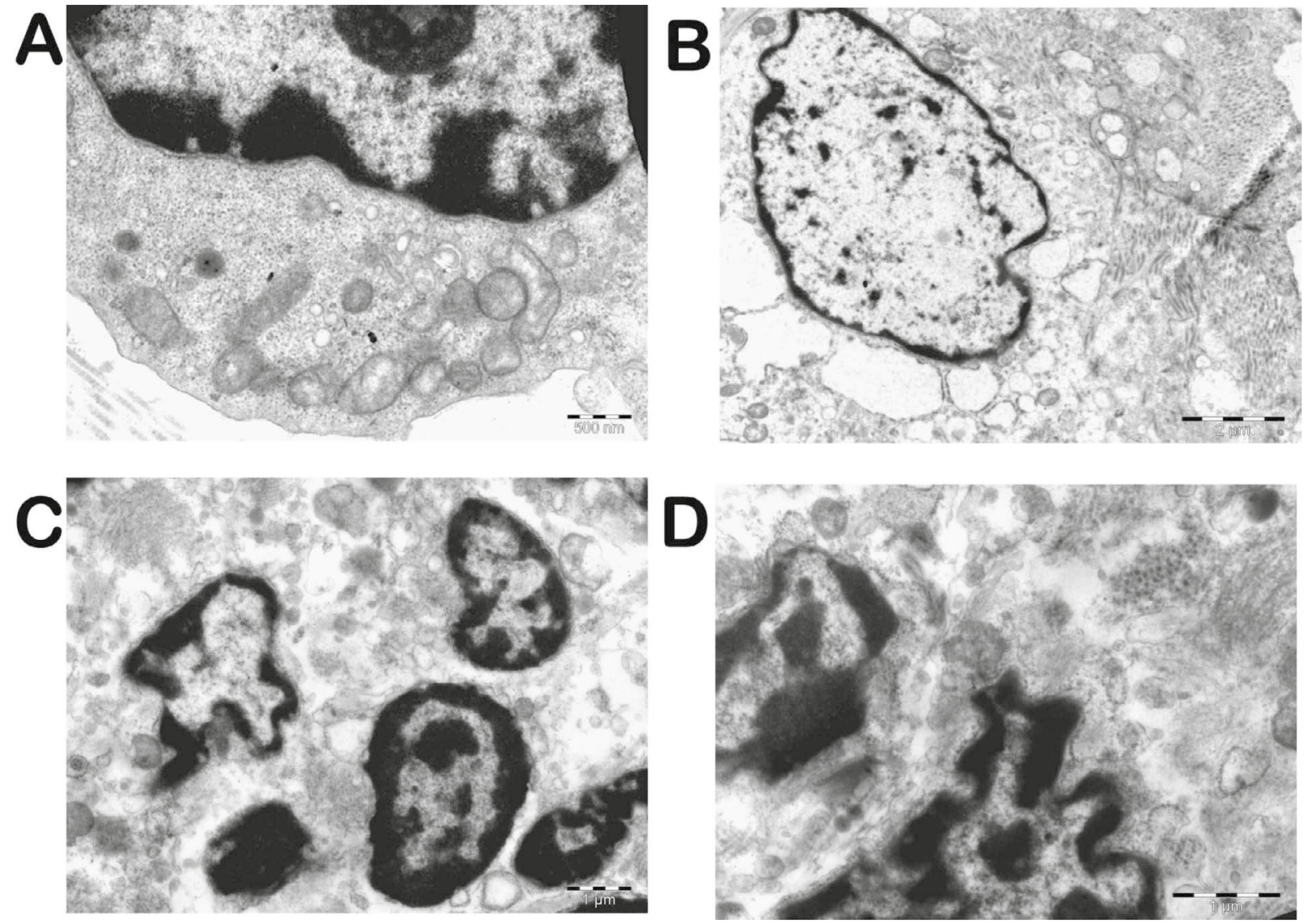

Figure 6. Electronmicro-graph cell nuclei visible in reference and endometriosis groups

apoptosis in the HCC cell line in vitro and significantly inhibit tumor growth in the mouse xenograft model [63]. In the endometriosis cells examined by us, LSF expression was lower than in the control cells. How it affects the development of endometriosis and whether this factor could be helpful in diagnosing endometriosis requires further research.

\section{Funding}

This study was funded by a grant from the Medical University of Lublin, no DS 120, DS 128 and MB 128.

\section{Conflict of interest}

The authors declare that they have no competing interests.

\section{Ethical approval}

The study was approved by the Ethics Committee of the Medical University of Lublin (Lublin, Poland; Resolution of the Bioethics Committee no. 0254/263/2011).

\section{Informed consent statement}

Informed consent was obtained from all individual participants included in the study.

\section{Acknowledgements}

The authors are very grateful that this study was proofread by Dr. Mark Ó Fionnáin, a native speaker and lecturer in the English Institute of the John Paul II Catholic University of Lublin, Poland.

\section{Availability of data and materials}

The datasets used and/or analyzed during the current study are available from the corresponding author on reasonable request.

\section{REFERENCES}

1. Bulun SE. Endometriosis. N Engl J Med. 2009; 360(3): 268-279, doi: 10.1056/NEJMra0804690, indexed in Pubmed: 19144942.

2. Broniarczyk J, Olejnik-Schmidt A, Luczak MW, et al. Analysis of expression and structure of the TSG 101 gene in cervical cancer cells. Int J Mol Med. 2010; 25(5): 777-783, doi: 10.3892/ijmm_00000404.

3. Missmer SA, Hankinson SE, Spiegelman D, et al. Incidence of laparoscopically confirmed endometriosis by demographic, anthropometric, and lifestyle factors. Am J Epidemiol. 2004; 160(8): 784-796, doi: 10.1093/aje/kwh275, indexed in Pubmed: 15466501.

4. Rogers PAW, D'Hooghe TM, Fazleabas A, et al. Priorities for endometriosis research: recommendations from an international consensus workshop. Reprod Sci. 2009; 16(4): 335-346, doi: 10.1177/1933719108330568, indexed in Pubmed: 19196878. 
5. Krempler A, Henry M, Triplett A, et al. Targeted deletion of the Tsg101 gene results in cell cycle arrest at $\mathrm{G} 1 / \mathrm{S}$ and $\mathrm{p} 53$-independent cell death. Journal of Biological Chemistry. 2002; 277(45): 43216-43223, doi: 10.1074/jbc.m207662200.

6. Wagner KU, Krempler A, Qi Y, et al. Tsg101 is essential for cell growth, proliferation, and cell survival of embryonic and adult tissues. Mol Cell Biol. 2003; 23(1): 150-162, doi: 10.1128/MCB.23.1.150-162.2003, indexed in Pubmed: 12482969.

7. $\mathrm{Kim} \mathrm{CH}$, Heath $\mathrm{C}$, Bertuch $\mathrm{A}$, et al. Specific stimulation of simian virus 40 late transcription in vitro by a cellular factor binding the simian virus 40 21-base-pair repeat promoter element. Proc Natl Acad Sci U S A. 1987; 84(17): 6025-6029, doi: 10.1073/pnas.84.17.6025, indexed in Pubmed: 2819862

8. Wilanowski T, Tuckfield A, Cerruti L, et al. A highly conserved novel family of mammalian developmental transcription factors related to Drosophila grainyhead. Mech Dev. 2002; 114(1-2):37-50, doi: 10.1016/s09254773(02)00046-1, indexed in Pubmed: 12175488.

9. Watanabe $M$, Yanagi $Y$, Masuhiro $Y$, et al. A putative tumor suppressor, TSG101, acts as a transcriptional suppressor through its coiled-coil domain. Biochemical and Biophysical Research Communications. 1998; 245(3): 900-905, doi: 10.1006/bbrc.1998.8547.

10. Hansen U, Owens L, Saxena U. Transcription factors LSF and E2Fs: tandem cyclists driving G0 to S? Cell Cycle. 2014; 8(14): 2146-2151, doi: 10.4161/cc.8.14.9089.

11. Worley MJ, Welch WR, Berkowitz RS, et al. Endometriosis-associated ovarian cancer: a review of pathogenesis. Int J Mol Sci. 2013; 14(3): 5367-5379, doi: 10.3390/ijms 14035367, indexed in Pubmed: 23466883.

12. Singer G, Kurman RJ, Chang HW, et al. Diverse tumorigenic pathways in ovarian serous carcinoma. Am J Pathol. 2002; 160(4): 1223-1228, doi: 10.1016/s0002-9440(10)62549-7, indexed in Pubmed: 11943707.

13. Wiegand KC, Shah SP, Al-Agha OM, et al. ARID1 A mutations in endometriosis-associated ovarian carcinomas. N Engl J Med. 2010;363(16): 15321543, doi: 10.1056/NEJMoa1 008433, indexed in Pubmed: 20942669.

14. Bischoff F, Simpson J. Genetic Basis of Endometriosis. Annals of the New York Academy of Sciences. 2004; 1034(1): 284-299, doi: 10.1196/annals.1335.030.

15. Zondervan KT, Cardon LR, Kennedy SH. The genetic basis of endometriosis. Curr Opin Obstet Gynecol. 2001; 13(3): 309-314, doi: 10.1097/00001703-200106000-00011, indexed in Pubmed: 11396656.

16. Kim H, Park JuH, Ku SY, et al. Association between endometriosis and polymorphisms in insulin-like growth factors (IGFs) and IGF-I receptor genes in Korean women. Eur J Obstet Gynecol Reprod Biol. 2011; 156(1): 87-90, doi: 10.1016/j.ejogrb.2010.12.018, indexed in Pubmed: 21251749.

17. Meola J, Rosa e Silva JC, Dentillo DB, et al. Differentially expressed genes in eutopic and ectopic endometrium of women with endometriosis. Fertil Steril. 2010; 93(6): 1750-1773, doi: 10.1016/j.fertnstert.2008.12.058, indexed in Pubmed: 19200988.

18. Mandai M, Matsumura N, Baba T, et al. Ovarian clear cell carcinoma as a stress-responsive cancer: influence of the microenvironment on the carcinogenesis and cancer phenotype. Cancer Lett. 2011; 310(2): 129-133, doi: 10.1016/j.canlet.2011.06.039, indexed in Pubmed: 21802200.

19. Brahmkhatri VP, Prasanna C, Atreya HS. Insulin-like growth factor system in cancer: novel targeted therapies. Biomed Res Int. 2015; 2015:538019, doi: 10.1155/2015/538019, indexed in Pubmed: 25866791.

20. Ohlsson C, Mohan S, Sjögren K, et al. The role of liver-derived insulin-like growth factor-I. Endocr Rev. 2009; 30(5): 494-535, doi: 10.1210/er.20090010, indexed in Pubmed: 19589948.

21. Maki RG. Small is beautiful: insulin-like growth factors and their role in growth, development, and cancer. J Clin Oncol. 2010; 28(33): 4985-4995, doi: 10.1200/JCO.2009.27.5040, indexed in Pubmed: 20975071.

22. Vandomme J, Touil Y, Ostyn P, et al. Insulin-like growth factor 1 receptor and $\mathrm{p} 38$ mitogen-activated protein kinase signals inversely regulate signal transducer and activator of transcription 3 activity to control human dental pulp stem cell quiescence, propagation, and differentiation. Stem Cells Dev. 2014; 23(8): 839-851, doi: 10.1089/scd.2013.0400, indexed in Pubmed: 24266654.

23. Pagon Z, Volker J, Cooper GM, et al. Mammalian transcription factor LSF is a target of ERK signaling. J Cell Biochem. 2003; 89(4): 733-746, doi: 10.1002/jcb.10549, indexed in Pubmed: 12858339.

24. Batson SC, Sundseth R, Heath CV, et al. In vitro initiation of transcription by RNA polymerase II on in vivo-assembled chromatin templates. Mol Cell Biol. 1992; 12(4): 1639-1651, doi: 10.1128/mcb.12.4.1639-1651.1992, indexed in Pubmed: 1312666.
25. Friday BB, Adjei AA. Advances in targeting the Ras/Raf/MEK/Erk mitogen-activated protein kinase cascade with MEK inhibitors for cancer therapy. Clin Cancer Res. 2008; 14(2):342-346, doi: 10.1158/1078-0432. CCR-07-4790, indexed in Pubmed: 18223206.

26. Byron $S A$, Loch $D C$, Wellens $C L$, et al. Sensitivity to the MEK inhibitor E6201 in melanoma cells is associated with mutant BRAF and wildtype PTEN status. Mol Cancer. 2012; 11: 75, doi: 10.1186/1476-4598-11-75, indexed in Pubmed: 23039341.

27. Santhekadur PK, Rajasekaran D, Siddiq A, et al. The transcription factor LSF: a novel oncogene for hepatocellular carcinoma. Am J Cancer Res. 2012; 2(3): 269-285, indexed in Pubmed: 22679558.

28. Jiang $\mathrm{H}, \mathrm{Du}$ J, Jin J, et al. LSF expression and its prognostic implication in colorectal cancer. Int J Clin Exp Pathol. 2014; 7(9): 6024-6031, indexed in Pubmed: 25337247.

29. Ma XR, Edmund Sim UH, Pauline B, et al. Overexpression of WNT2 and TSG101 genes in colorectal carcinoma. Trop Biomed. 2008; 25(1): 46-57, indexed in Pubmed: 18600204.

30. Liu Dc, Yang ZI, Jiang S. Identification of PEG10 and TSG101 as carcinogenesis, progression, and poor-prognosis related biomarkers for gallbladder adenocarcinoma. Pathol Oncol Res. 2011; 17(4): 859-866, doi: 10.1007/s12253-011-9394-7, indexed in Pubmed: 21455631.

31. Lohrum MA, Vousden KH. Regulation and function of the p53-related proteins: same family, different rules. Trends Cell Biol. 2000; 10(5): 197-202, doi: 10.1016/s0962-8924(00)01736-0, indexed in Pubmed: 10754563.

32. Johnson NP, Hummelshoj L, Adamson GD, et al. World Endometriosis Society Sao Paulo Consortium. World Endometriosis Society consensus on the classification of endometriosis. Hum Reprod. 2017; 32(2): 315-324, doi: 10.1093/humrep/dew293, indexed in Pubmed: 27920089.

33. Bischoff F, Simpson JL. Genetic basis of endometriosis. Ann N Y Acad Sci. 2004; 1034: 284-299, doi: 10.1196/annals.1335.030, indexed in Pubmed: 15731320.

34. Hansen KA, Eyster KM. Genetics and genomics of endometriosis. Clin Obstet Gynecol. 2010;53(2):403-412, doi: 10.1097/GRF.0b013e3181db7ca1, indexed in Pubmed: 20436317.

35. Baranov VS, Osinovskaya NS, Yarmolinskaya MI. Pathogenomics of Endometriosis Development. Prime Archives in Molecular Biology. 2020, doi: 10.37247/pamb.1.2020.20.

36. Fung JN, Montgomery GW. Genetics of endometriosis: State of the art on genetic risk factors for endometriosis. Best Pract Res Clin Obstet Gynaecol. 2018; 50:61-71, doi: 10.1016/j.bpobgyn.2018.01.012, indexed in Pubmed: 29506960.

37. Loverro G, Maiorano E, Napoli A, et al. Transforming growth factor-beta 1 and insulin-like growth factor-1 expression in ovarian endometriotic cysts: a preliminary study. Int J Mol Med. 2001; 7(4): 423-429, doi: 10.3892/ijmm.7.4.423, indexed in Pubmed: 11254886.

38. Witsch $\mathrm{E}$, Sela $\mathrm{M}$, Yarden $\mathrm{Y}$. Roles for growth factors in cancer progression. Physiology (Bethesda). 2010; 25(2): 85-101, doi: 10.1152/physiol.00045.2009, indexed in Pubmed: 20430953.

39. Tang XM, Rossi MJ, Masterson BJ, et al. Insulin-like growth factor I (IGF-I), IGF-I receptors, and IGF binding proteins 1-4 in human uterine tissue: tissue localization and IGF-I action in endometrial stromal and myometrial smooth muscle cells in vitro. Biol Reprod. 1994; 50(5): 1113-1125, doi: 10.1095/biolreprod50.5.1113, indexed in Pubmed: 7517700.

40. Ivanga $\mathrm{M}$, Labrie $\mathrm{Y}$, Calvo E, et al. Temporal analysis of E2 transcriptional induction of PTP and MKP and downregulation of IGF-I pathway key components in the mouse uterus. Physiol Genomics. 2007; 29(1): 13-23, doi: 10.1152/physiolgenomics.00291.2005, indexed in Pubmed: 17361005.

41. Giudice LC, Dsupin BA, Gargosky SE, et al. The insulin-like growth factor system in human peritoneal fluid: its effects on endometrial stromal cells and its potential relevance to endometriosis. J Clin Endocrinol Metab. 1994; 79(5): 1284-1293, doi: 10.1210/jcem.79.5.7525631, indexed in Pubmed: 7525631.

42. Koutsilieris $M$, Mastrogamvrakis $G$, Lembessis $P$, et al. Increased insulin-like growth factor 1 activity can rescue KLE endometrial-like cells from apoptosis. Mol Med. 2001; 7(1): 20-26, indexed in Pubmed: 11474124.

43. Murphy LJ, Ghahary A. Uterine insulin-like growth factor-1: regulation of expression and its role in estrogen-induced uterine proliferation. Endocr Rev. 1990; 11(3): 443-453, doi: 10.1210/edrv-11-3-443, indexed in Pubmed: 2226350

44. Koutsilieris $\mathrm{M}$, Akoum $\mathrm{A}$, Lazure $\mathrm{C}$, et al. $\mathrm{N}$-terminal truncated forms of insulin-like growth factor binding protein-3 in the peritoneal fluid 
of women without laparoscopic evidence of endometriosis. Le groupe d'investigation en gynécologie. Fertil Steril. 1995; 63(2): 314-321, doi: 10.1016/s0015-0282(16)57362-2, indexed in Pubmed: 7531162.

45. Akoum A, Lemay A, Lajeunesse $Y$, et al. Immunohistochemical localization of insulin-like growth factor-binding protein-3 in eutopic and ectopic endometrial tissues. Fertil Steril. 1999; 72(6): 1085-1092, doi: 10.1016/s0015-0282(99)00443-4, indexed in Pubmed: 10593386.

46. Bache $\mathrm{K}$, Brech A, Mehlum A, et al. Hrs regulates multivesicular body formation via ESCRT recruitment to endosomes. Journal of Cell Biology. 2003; 162(3): 435-442, doi: 10.1083/jcb.200302131.

47. McCampbell AS, Broaddus RR, Loose DS, et al. Overexpression of the insulin-like growth factor I receptor and activation of the AKT pathway in hyperplastic endometrium. Clin Cancer Res. 2006; 12(21): 6373-6378, doi: 10.1158/1078-0432.CCR-06-0912, indexed in Pubmed: 17085648.

48. Broniarczyk J, Warowicka A, Kwaśniewska A, et al. Expression of TSG101 protein and LSF transcription factor in HPV-positive cervical cancer cells. Oncology Letters. 2014; 7(5): 1409-1413, doi: 10.3892/ol.2014.1967.

49. Young TW, Rosen DG, Mei FC, et al. Up-regulation of tumor susceptibility gene 101 conveys poor prognosis through suppression of p21 expression in ovarian cancer. Clin Cancer Res. 2007; 13(13): 3848-3854, doi: 10.1158/1078-0432.CCR-07-0337, indexed in Pubmed: 17606716.

50. Young TW, Mei FC, Rosen DG, et al. Up-regulation of tumor susceptibility gene 101 protein in ovarian carcinomas revealed by proteomics analyses. Mol Cell Proteomics. 2007; 6(2): 294-304, doi: 10.1074/mcp. M600305-MCP200, indexed in Pubmed: 17110434.

51. Li L, Francke U, Cohen SN. The TSG 101 tumor susceptibility gene is located in chromosome 11 band p15 and is mutated in human breast cencer. Cell . 1997; 88: 143-154.

52. Santhekadur PK, Rajasekaran D, Siddiq A. The transcription factor LSF: a novel oncogene for hepatocellullar carcinoma.Am J Cancer Res. Am J Cancer Res. 2012; 2: 269-285.

53. Drouin EE, Schrader CE, Stavnezer J, et al. The ubiquitously expressed DNA-binding protein late SV40 factor binds Ig switch regions and represses class switching to IgA. J Immunol. 2002; 168(6): 2847-2856, doi: 10.4049/jimmunol.168.6.2847, indexed in Pubmed: 11884454
54. Zambrano N, Minopoli G, de Candia P, et al. The Fe65 adaptor protein interacts through its PID1 domain with the transcription factor CP2/LSF/LBP1. J Biol Chem. 1998; 273(32): 20128-20133, doi: 10.1074/jbc.273.32.20128, indexed in Pubmed: 9685356.

55. Fan $\mathrm{R}$, Chen $\mathrm{P}$, Zhao Di, et al. Cooperation of deregulated Notch signaling and Ras pathway in human hepatocarcinogenesis. J Mol Histol. 2011;42(5): 473-481, doi: 10.1007/s10735-011-9353-3, indexed in Pubmed: 21892768.

56. Ras $\mathrm{P}$, Stifani $\mathrm{S}$, Blaumeller $\mathrm{CM}$, et al. Alterations in Notch signaling in neoplastic lesions of human cevix. Proc Natl Acad Sci USA . 1995; 92: 6414-6418.

57. Leethanakul C, Patel V, Gillespie J, et al. Distinct pattern of expression of differentiation and growth-related genes in squamous cell carcinomas of the head and neck revealed by the use of laser capture microdissection and cDNA arrays. Oncogene. 2000; 19(28): 3220-3224, doi: 10.1038/sj.onc.1203703, indexed in Pubmed: 10918578.

58. Westhoff B, Colaluca IN, D'Ario G, et al. Alterations of the Notch pathway in lung cancer. Proc Natl Acad Sci U S A. 2009; 106(52): 22293-22298, doi: 10.1073/pnas.0907781106, indexed in Pubmed: 20007775.

59. Zhang Y, Li B, Ji ZZ, et al. Notch1 regulates the growth of human colon cancers. Cancer. 2010; 116(22): 5207-5218, doi: 10.1002/cncr.25449.

60. Okuhashi Y, Itoh $\mathrm{M}, \mathrm{Nara} \mathrm{N}$, et al. Effects of gamma-secretase inhibitors on the growth of leukemia cells. Anticancer Res. 2010; 30(2): 495-498, indexed in Pubmed: 20332460.

61. de Miranda NF, Georgiou K, Chen L, et al. Exome sequencing reveals novel mutation targets in diffuse large B-cell lymphomas derived from Chinese patients. Blood. 2014; 124(16): 2544-2553, doi: 10.1182/blood-2013-12-546309, indexed in Pubmed: 25171927.

62. Rajasekaran D, Siddiq A, Willoughby JLS, et al. Small molecule inhibitors of Late SV40 Factor (LSF) abrogate hepatocellular carcinoma (HCC): Evaluation using an endogenous HCC model. Oncotarget. 2015; 6(28): 26266-26277, doi: 10.18632/oncotarget.4656, indexed in Pubmed: 26313006.

63. GrantTJ, Bishop JA, Christadore LM, et al. Antiproliferative small-molecule inhibitors of transcription factor LSF reveal oncogene addiction to LSF in hepatocellular carcinoma. Proc Natl Acad Sci U S A. 2012; 109(12): 4503 -4508, doi: 10.1073/pnas.1121601109, indexed in Pubmed: 22396589. 